\title{
$\begin{array}{lllllllllllllll} & X & C & H & A & N & G & E\end{array}$
}

\section{What's the Evidence on Evidence-Based Management?}

by Trish Reay, Whitney Berta, and Melanie Kazman Kohn

\begin{abstract}
Executive Overview
In this article, we respond to recent calls for increased use of evidence-based management (EBMgt) by conducting a systematic review of the literature to answer the following questions: (1) Is there a substantial literature concerning the concept of evidence-based management? (2) What is the quality of evidence (where it exists) regarding evidence-based management? and (3) Is there evidence that employing evidence-based management will improve organizational performance? We applied an assessment rubric based on ranking systems developed in evidence-based medicine to evaluate the strength of evidence. We found that a large number of articles are published on the topic, but most provide encouragement to adopt EBMgt based on opinion and anecdotal information. We call for increased research to generate stronger evidence related to the impact of EBMgt on organizational performance.
\end{abstract}

E vidence-based management (EBMgt) is the systematic use of the best available evidence to improve management practice (Pfeffer \& Sutton, 2006; Rousseau, 2006). There are a number of outspoken and eloquent proponents of EBMgt, but in particular Denise Rousseau has been a strong voice noting the apparent scarcity of management practice and decision making predicated on EBMgt. Many of the calls to action reference a relatively more mature discussion in the medical and health care literatures that promotes the use of "best available evidence" in medical decision making. Champions of the evidence-based medicine movement advise clinicians to make decisions based on the best available evidence-ide-

The authors thank Dean Darwent for timely and thorough research assistance and Kathy West (Business Librarian, University of Alberta) for helpful advice. ally gathered from rigorous methods using large patient samples (e.g., randomized controlled trials). Further, the concept of evidence-based medicine is dynamic; knowledge acquired at the time clinicians first receive their training is augmented by their subsequent experience as practitioners and refreshed through knowledge transfer efforts that constantly and reliably convey the latest research evidence to practitioners. In the latter case, knowledge transfer relies on the abilities of researchers to translate the research into a format that is meaningful to practitioners, and the abilities of the practitioners to critically assess the research in terms of its rigor and its potential to improve patient outcomes.

Rousseau and colleagues have championed a similar approach in the management and organization sciences, advocating that managers make

\footnotetext{
* Trish Reay (trish.reay@ualberta.ca) is an Associate Professor in the Department of Strategic Management and Organization at the University of Alberta School of Business.

Whitney Berta (whit.berta@utoronto.ca) is Associate Professor, Health Services Organization \& Management, and Director, MSc/PhDHealth Services Research Program, Health Policy, Management and Evaluation, Faculty of Medicine, University of Toronto.

Melanie Kazman Kohn (kohnm@smh.toronto.on.ca) is a Ph.D. student in Health Policy, Management and Evaluation, Faculty of Medicine, University of Toronto, and Director, Corporate Strategic Projects, St. Michael's Hospital, Toronto, Ontario.
} 
decisions based on "scientific evidence and local business evidence” (2008, p. 10). Reactions to this call for EBMgt have been diverse. While Rousseau and her colleagues advocate for EBMgt, others are more cautious, suggesting that changing contexts, or the pluralistic nature of organizations, may preclude an EBMgt approach. Others contend that researchers and managers have long adhered to the notion of EBMgt, while some have suggested that management is not a profession and therefore may not be amenable to scientific study that aims to identify generally applicable "best management practices" (Cascio, 2007; Rousseau, 2006; Rousseau \& McCarthy, 2007; Walshe \& Rundall, 2001).

As recipients and beneficiaries of management education that has been grounded in research evidence, and as a team that is collectively experienced in research, teaching, and management, we reacted, as did others, with some skepticism to the recent suggestions, circa 2005, that managers have not been practicing evidence-based management and that researchers are not sufficiently concerned with the situation. We felt that one way to resolve some of the controversy, and possibly advance the state of the art regarding EBMgt, was to conduct a systematic review of the literature on EBMgt.

Here, we report on our review of the literature and document the existing evidence related to EBMgt. Through our systematic review we assess the volume, type, and quality of evidence on EBMgt. We also take the issue one step further by exploring whether there is evidence to support a positive relationship between EBMgt and organizational performance. Our work is driven by one overarching question: What is the evidence on evidence-based management? More specifically, we focused on answering the following questions:

(1) Is there a substantial literature concerning the concept of evidence-based management?

(2) What is the quality of the evidence (where it exists) regarding evidence-based management?

(3) Is there evidence that employing evidence- based management will improve organizational performance?

\section{Methods}

W e completed a systematic literature review of articles concerning evidence-based management written in English through 2008 and accessible through electronic management databases. The results of our review are described in the Results section that follows. In this section, we describe our review process.

\section{Generation of Keywords Listing}

We used a two-step process to generate our list of keywords to facilitate an electronic search of library databases. First, in addition to the obvious choice of "evidence-based management" and its variants, we formulated an initial list of search terms derived from the broad definition of evidence-based management offered by Rousseau et al.: "the complementary use of scientific evidence and local business evidence" to manage organizations effectively (2008, p. 10). With advice from a librarian with expertise in searching business periodical databases, we augmented our list of keywords with synonymous and related terms.

Using the final list of keywords (see Table 1) we searched the following electronic databases: EBSCO, ABI Inform, and Web of Science (ex-

\section{Table 1}

\section{Keywords Listing}

\begin{tabular}{|l|}
\hline Evidence-based management \\
\hline Evidence-based decision making \\
\hline Organizational decision making \\
\hline Research-to-practice \\
\hline Strategic decision making \\
\hline Implementation science \\
\hline Knowledge utilization \\
\hline Research utilization \\
\hline Best practice \\
\hline Best evidence \\
\hline Management research \\
\hline Evidence-informed decision making \\
\hline Knowledge translation \\
\hline Knowledge transfer \\
\hline
\end{tabular}




\section{Table 2}

\section{Systematic Review Template}

\begin{tabular}{|l|l|}
\hline \multicolumn{1}{|c|}{ Column Title (Position) } & \\
\hline Reference number (col. A) & To facilitate retrieval and secondary reviews \\
\hline Full reference (cols. B-G) & To facilitate article retrieval \\
\hline Country of origin (col. H) & To facilitate article review and comparion \\
\hline Inclusion criteria met? (Y/N) (col. I) & Q: Is this article about the concept of evidence-based management? \\
\hline Management area (col. J) & $\begin{array}{l}\text { Q: What management area does this paper address? For example, decision making, human resources and staffing, } \\
\text { leadership, information systems, structure, strategy, marketing, general EBMgt, other (specify) }\end{array}$ \\
\hline Article purpose/focus (col. K) & Empirical research, literature review/theory overview, theoretical framework/model, opinion piece/call to action, case study \\
\hline Basis of opinion (col. L) & $\begin{array}{l}\text { Q: If an opinion piece/call to action, what is the basis of opinion? For example, anecdotes, literature review, personal } \\
\text { experience, other (specify) }\end{array}$ \\
\hline Intended target audience (col. M) & $\begin{array}{l}\text { For example, lay (executives, middle managers, practitioners, cross-functional/interdisciplinary decision-making team), } \\
\text { students, policy makers, researchers, other (specify) }\end{array}$ \\
\hline Sector/organization (col. N) & Specify targeted sector and/or organization type \\
\hline Level of analysis (col. 0) & Individual, organizational, institutional, system \\
\hline Methodology (col. P) & Quantitative (specify), qualitative (specify), mixed methods (specify), other (specify) \\
\hline Data source (col. Q) & Administrative, survey, interview, focus group, document review, other (specify) \\
\hline Type of article (col. R) & Promising practices, transitional, evidence-based practice, context, mechanisms, transferability, opinion \\
\hline Level of evidence (col. S) & $\begin{array}{l}\text { A levels of evidence "rubric" used by one of us in prior studies evaluating clinical research evidence (see Barnsley et al., 2005) } \\
\text { and adapted from the original work of D'Agostino \& Kwan (1995) was used here. See Table } 3 \text { for description }\end{array}$ \\
\hline Comments (col. T) & Free-form comments regarding article in light of study objective and comparable other articles reviewed \\
\hline
\end{tabular}

cluding articles on evidence-based medicine). We selected these databases because we were interested in the entire range of work in the area of EBMgt, where the range is anchored by opinionbased articles and large-sample randomized empirical studies, and all management settings, regardless of industry and inclusive of all management levels.

\section{Abstract Reviews and Exclusions}

Our initial search generated 216 articles. One researcher and a research assistant reviewed the abstracts to exclude easily identifiable errors of three types: duplicate entries, book reviews, and articles using the term "evidence-based" but referring to evidence-based medicine or evidencebased government policy, since these areas were not relevant to our research question. The exclusions resulted in 164 remaining articles. We then conducted a hand search to identify missed articles that met our inclusion criteria. This resulted in an additional five articles, which gave us a total of 169 articles, all of which were subjected to a full review following the process described below.

\section{Article Reviews}

Since we were a research team of three, each of us read and reviewed one-third of the articles as a first step. Next, we conducted a further round of reviews so that all coding decisions (as outlined below) were made with the agreement of at least two researchers. We developed an Excel worksheet that served as our review template for each of the 169 articles. On reading and analyzing the full set of articles, we excluded another 25 articles that did not address the concept of EBMgt. The final result was 144 articles for further analysis. Each of the articles was coded according to the parameters listed in Table 2.

To assess the strength of evidence related to EBMgt in a systematic way across all 144 articles, we modified a rubric for evaluating the quality of medical research developed by D'Agostino and Kwan (1995). ${ }^{1}$ In Table 3 we show the comparison between evaluation standards used in medical

\footnotetext{
${ }^{1}$ Numerous assessment rubrics are used to evaluate medical research; one of the most widely used was developed by the NHS R\&D Centre for Evidence-Based Medicine. The rubric we used was a somewhat less complicated one, appropriate for this assessment of the management literature,
} 


\section{Table 3}

\section{Levels of Evidence in Medical Research vs. Management Research}

\begin{tabular}{|c|c|c|c|}
\hline Level of Evidence & Medical Research & Management Research & Examples in Dataset \\
\hline $\begin{array}{l}\text { Level } 1 \text { evidence is } \\
\text { generated } \\
\text { through... }\end{array}$ & $\begin{array}{l}\text { Large-sample randomized } \\
\text { controlled trials (RCTs) that are } \\
\text { either (a) positive, with small risks } \\
\text { of false positive conclusions, or (b) } \\
\text { negative, with small risks of false } \\
\text { negative conclusions, or (c) meta- } \\
\text { analysis. }\end{array}$ & RCTs or meta-analyses. & None identified \\
\hline $\begin{array}{l}\text { Level } 2 \text { evidence } \\
\text { emerges from... }\end{array}$ & $\begin{array}{l}\text { Small-sample RCTs that show either } \\
\text { (a) positive trends that are not } \\
\text { statistically significant, with big } \\
\text { risks of false positive conclusions, } \\
\text { or (b) no impressive trends, but } \\
\text { large risks of false negative } \\
\text { conclusions, or (c) a systematic } \\
\text { literature review. }\end{array}$ & $\begin{array}{l}\text { (a) A high-quality literature review } \\
\text { that is replicable and } \\
\text { comprehensive and provides a } \\
\text { synthesis and actionable } \\
\text { recommendations predicated on } \\
\text { the synthesis or (b) a systematic } \\
\text { literature review. }\end{array}$ & $\begin{array}{l}\text { Heenan \& Addleman (1976); Beyer \& Trice (1982); } \\
\text { O'Driscoll \& Murray (1998); Walshe \& Rundall } \\
\text { (2001); Young (2002); Finkler \& Ward (2003); } \\
\text { Hewison (2003); Ovretveit (2005); Johnson \& } \\
\text { Austin (2006); Kovner \& Rundall (2006); MacPhee, } \\
\text { Ellis, \& Sanchez (2006); Morrison, Brown, \& Smit } \\
\text { (2006); Ployhart (2006); Arndt \& Bigelow (2007); } \\
\text { Coldwell (2007); Hamlin (2007); Kumar \& } \\
\text { Grimmer-Somers (2007); Penin (2007); Hall \& } \\
\text { Jennings (2008) }\end{array}$ \\
\hline $\begin{array}{l}\text { Level } 3 \text { evidence is } \\
\text { garnered } \\
\text { through... }\end{array}$ & $\begin{array}{l}\text { Observational studies, } \\
\text { retrospective case control studies, } \\
\text { or prospective cohort studies. Data } \\
\text { from these studies help us } \\
\text { understand what variables might } \\
\text { be useful to consider as cause and } \\
\text { effect variables. }\end{array}$ & $\begin{array}{l}\text { Comparative, multisite case studies } \\
\text { or large-sample quantitative } \\
\text { studies involving data collected } \\
\text { from more than one site } \\
\text { (organization). }\end{array}$ & $\begin{array}{l}\text { Drucker (1955); Shadur, Rodwell, \& Bamber } \\
\text { (1995); Gill \& Wong (1998); Sjoblom (1998); } \\
\text { Gooderham, Nordhaug, \& Ringdal (1999); Ghosh \& } \\
\text { Lusch (2000); Nutt (2000); Otley \& Pollanen } \\
\text { (2000); Hamlin (2002); Drake \& Davies (2006); } \\
\text { Geppert \& Williams (2006); Greene (2007); Rynes, } \\
\text { Giluk, \& Brown (2007) }\end{array}$ \\
\hline $\begin{array}{l}\text { Level } 4 \text { evidence is } \\
\text { gathered } \\
\text { through... }\end{array}$ & $\begin{array}{l}\text { The use of historical controls. One } \\
\text { uses past experience as a control } \\
\text { and assigns all new patients to } \\
\text { receive a new intervention. It is } \\
\text { important to understand clearly } \\
\text { what happened to the patients in } \\
\text { the past, before a new intervention } \\
\text { is introduced. }\end{array}$ & $\begin{array}{l}\text { Small-sample, single-site } \\
\text { qualitative or quantitative studies. } \\
\text { These studies are theoretically } \\
\text { motivated and are completed by } \\
\text { trained (management) researchers } \\
\text { who have (at most) an arm's- } \\
\text { length relationship with the } \\
\text { organization under study; the } \\
\text { "voice" of these studies is } \\
\text { objective. }\end{array}$ & $\begin{array}{l}\text { McClatchey (2001); Syreft (2003); Blair (2004); } \\
\text { Dennis \& Componation (2004); Huffman \& Cowan } \\
\text { (2004); Adams \& Frost (2006); Watson, Wixom, } \\
\text { Hoffer, Andersen-Lehman, \& Reynolds (2006); } \\
\text { Alexander, Hearld, Jiang, \& Fraser (2007); } \\
\text { Cromwell, Drozd, Smith, \& Trisolini (2007); Mishra, } \\
\text { Anand, \& Kodali (2007); Zell, Glassman, \& Duron } \\
\text { (2007); Arnott \& O'Donnell (2008) }\end{array}$ \\
\hline $\begin{array}{l}\text { Level } 5 \text { evidence is } \\
\text { generated } \\
\text { through... }\end{array}$ & $\begin{array}{l}\text { Descriptive clinical studies. This } \\
\text { approach can be useful in studying } \\
\text { how to apply a new technique, } \\
\text { identifying the problems associated } \\
\text { with it, and seeing how it works } \\
\text { with different groups of patients. }\end{array}$ & $\begin{array}{l}\text { Descriptive studies and/or self- } \\
\text { report stories. These studies } \\
\text { generally include observations, } \\
\text { admonitions, and } \\
\text { recommendations of import to } \\
\text { managers. Early papers important } \\
\text { to the then "new" area of } \\
\text { evidence-based management } \\
\text { offered nascent theory bolstered } \\
\text { by Level } 5 \text { evidence. }\end{array}$ & $\begin{array}{l}\text { Churchman (1964); Drucker (1967); Arzac } \\
\text { (1986); Darr (1998); Jameson (2001); Dey } \\
\text { (2002); Williams (2002); Berry \& Bendapudi } \\
\text { (2003); Bucher, Birkenmeier, Brodbeck, \& } \\
\text { Escher (2003); Christensen \& Raynor (2003); } \\
\text { Chan, Morton \& Shekelle (2004); Trangle } \\
\text { (2004); Weischedel, Matear, \& Deans (2005); } \\
\text { Pfeffer \& Sutton (2006); Graniere (2006); Saver } \\
\text { (2006); Heinrich (2007); Rousseau \& McCarthy } \\
\text { (2007); Suttell (2007); Rundall, Martell, Arroyo, } \\
\text { McCurdy, Graetz, Neuwirth, Curtis, Schmittdiel, } \\
\text { Gibson, \& Hsu (2007); Unknown (2007); } \\
\text { Greenwood \& Cleeve (2008); Schwarz \& Murphy } \\
\text { (2008) }\end{array}$ \\
\hline
\end{tabular}




\section{Table 3}

\section{Continued}

\begin{tabular}{|c|c|c|c|}
\hline Level of Evidence & Medical Research & Management Research & Examples in Dataset \\
\hline $\begin{array}{l}\text { Level } 6 \text { evidence is } \\
\text { based on... }\end{array}$ & $\begin{array}{l}\text { The opinion of respected } \\
\text { authorities or expert committees } \\
\text { without additional data. This is the } \\
\text { weakest type of evidence. }\end{array}$ & $\begin{array}{l}\text { The opinion of respected } \\
\text { authorities or expert committees } \\
\text { without additional data. Some } \\
\text { papers offer anecdotal evidence as } \\
\text { a means of supporting expressed } \\
\text { opinions. This is the weakest type } \\
\text { of evidence. }\end{array}$ & $\begin{array}{l}\text { Conant (1948); Lipstein (1961); Ozcan \& Smith } \\
\text { (1998); Stewart (1998); Kovner, Elton, Billings, \& } \\
\text { Short (2000); Rosengard (2000); Wenger \& Snyder } \\
\text { (2000); Cudney, Cox, \& Baugh (2002); } \\
\text { Gunasekaran (2002); Lewis \& Latney (2002); } \\
\text { Taylor (2002); Finkler (2004); Grazier (2004); } \\
\text { Hewison (2004); Kaufman (2004); Sahney (2004); } \\
\text { Sensmeier (2004); White (2004); MarStravic } \\
\text { (2005); Mehta (2005); Poulos (2005); Tunis } \\
\text { (2005); Alexander (2006); Appelt \& Hauser } \\
\text { (2006); Bansal (2006); Berman (2006); Brown } \\
\text { (2006); Damore (2006); Dwyer (2006); Fine } \\
\text { (2006); Fitzpatrick (2006); Ginter \& Swayne } \\
\text { (2006); Hader (2006); Learmonth \& Harding } \\
\text { (2006); Leavitt (2006); Mankins \& Steele (2006); } \\
\text { Millet (2006); Myers \& Meccariello (2006); } \\
\text { Parrington (2006); Pfeffer \& Sutton (2006a, } \\
\text { 2006b, 2006c, 2006d, 2006e, 2006f, 2006g); } \\
\text { Rousseau (2006); Shortell (2006); Thomas (2006); } \\
\text { Trick (2006); Zuckerman (2006); Arbaugh (2007); } \\
\text { Bradshaw (2007); Cascio (2007); Cohen (2007); } \\
\text { Fisher \& Robertson (2007); Goto (2007); Guest } \\
\text { (2007); Haeger (2007); Henry (2007); Klimoski } \\
\text { (2007); Pfeffer \& Sutton (2007a, 2007b); } \\
\text { Rousseau (2007); Rundall (2007); Rynes (2007); } \\
\text { Saari (2007); Szabla (2007); Walton (2007); } \\
\text { Bentley (2008); Church, Baker, \& Berry (2008); } \\
\text { Kearns (2008); Learmonth (2008); Morrell (2008); } \\
\text { Phillips (2008); Ruark (2008); Walter (2008) }\end{array}$ \\
\hline
\end{tabular}

Full references available from the authors.

research (Levels 1 through 6) and the evaluation standards we used for management research. Modifications were necessary because medical research is geared toward randomized controlled trials (RCTs) as the "gold standard,"2 while RCTs are seldom conducted in the social sciences, where complex systems necessitate research designs that can accommodate contextual factors (Auerbach, Landefeld, \& Shojania, 2009). By following the

that originated with D'Agostino and Kwan (1995) and was subsequently modified by Barnsley et al. (2006) to include Level 6-Expert Opinion.

${ }^{2}$ In fact, this is a matter of contention within the medical sciences; since the 1990s (Feinstein \& Horwitz, 1997), evaluation scientists have argued that RCTs fail to take into account nonaverage individuals who comprise subgroups with different clinical features. More recently, scholars have decried the absence of consideration of the social context in which clinical decisions are made in the generation of medical research evidence and have noted the irony of the existence of an array of tools-not just one-that have been developed to assess the quality of medical evidence (Upshur, 2000, 2002, 2003). principles that differentiate one level from another in medical research, our modified rubric allowed us to categorize management articles according to the strength of evidence generated. The strongest level of evidence we observed was Level 2; the weakest and most frequently referenced was Level 6.

\section{Results}

B elow we present the results of our literature review, grouped according to the three research questions we identified at the start of our study.

\section{(1) Is There a Substantial Literafure Concerning the Concept of Evidence-Based Management?}

Our literature search revealed a large number of articles (144) related to the concept of EBMgt 
published as early as 1948 through to our designated endpoint of 2008. Figure 1 shows the number of EBMgt-focused publications by year over the study interval.

The earliest publication in our dataset was Conant (1948) in the Harvard Business Review. It focused on technology decision making in industries reliant on primary research in the basic sciences, noting the gap between basic science research and practitioners who made decisions with respect to adopting new technology. Between 1948 and 1995, only eight papers on EBMgt were published. Among them, three articles stood out as particularly discerning: Drucker $(1955,1967)$ and Beyer and Trice (1982).

Drucker's 1955 paper was the first to systematically lay out the central tenets of "management science"-the application of systematic methodology to the job of managing in the business enterprise. His phraseology was similar to that found in contemporary definitions of EBMgt, where management science needs to "arm the manager's imagination" and "supply him with the vision needed to make rational decisions in respect to the business enterprise," and should not serve as a substitute for decision and judgment but should "supply methods for making possible more effective decisions and more informed judgment" (p. 123). Drucker advised that management science (EBMgt) was not a prescription, but should be regarded as a "general methodology, a synthesizing and integrating logic" (p. 124) that must apply to all areas of management. Drucker's 1967 paper cited evidence from an array of case studies including political decision-making scenarios, and offered a systematic process model for executive and management decision makers. Beyer and Trice (1982) highlighted underutilization of organizational research as a significant problem, ad- dressing the issue from the standpoint of researchers desiring to enhance research uptake and utilization of management practices. They concluded with recommendations, based on a synthesis of findings from previously published studies, for enhancing research utilization among management practitioners and for improving research on research utilization.

Since 1998 there has been increased attention on the concept of EBMgt. Six articles were published in 1998, each focused on the application of evidence to decision making, in particular functional areas including human resources, finance, accounting, and health care management. Articles published in 2000 (6), 2001 (3), and 2002 (10) largely offered advice to executives about the potential benefits of using research evidence in strategic decision making. During this time period we identified only two articles based on strong research evidence that discussed issues related to EBMgt. Walshe and Rundall (2001) pointed to cultural and contextual differences experienced by health care practitioners compared to health care managers as an explanation for slower uptake of evidence-based practice by managers. They advocated the development of cultures of "learning through research" as the way to make improvements. Similarly, Young's (2002) systematic review of the literature showed that evidence-based practice was generally accepted as the best approach to clinical practice, and EBMgt was considered the corollary by which managerial practice could be accountable. Young's review also supported the development of an EBMgt culture as a way to improve the use of research evidence.

Six articles published in 2003 addressed EBMgt. One of these, a review by Hewison (2003), concluded that there was no firm "evidence base" to demonstrate the effectiveness of

\section{Figure 1}

Number of Articles Published per Year, 1948-2008

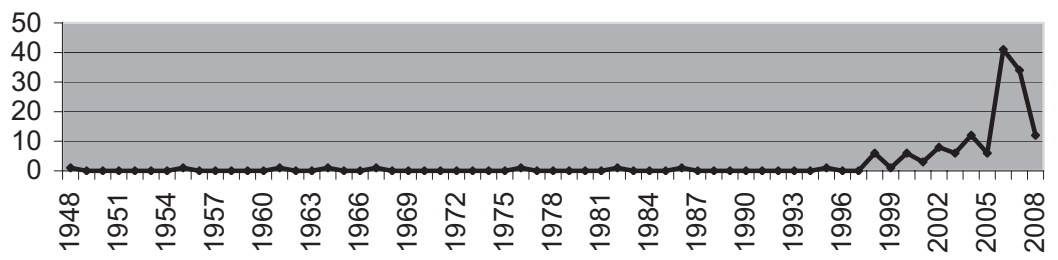


management practices in health care settings. In 2004 and 2005 there was a large increase in the number of publications concerning EBMgt (12 and 9 articles respectively). Only one was based on strong research evidence. This literature review (Ovretveit, 2005) found that while admonitions for committed leadership initiatives were prevalent, research evidence demonstrating the effects of leadership on organizational performance was scarce and lacking in rigor. There was a marked increase in the number of EBMgt articles in 2006 (43) and 2007 (35). In 2008, 12 articles were published. Over these three years, most articles were opinion pieces; however, an increasing number were based on stronger evidence. Several of the papers published over this interval reflected a new focus on knowledge translation.

The majority of articles we reviewed were in favor of EBMgt, including a few that pointed out potential problems with implementation. Of the 144 articles we reviewed, we identified only three opinion articles and one review article that advised against EBMgt. Based on their review, Arndt and Bigelow (2007) criticized the seemingly blind advocacy for EBMgt in general, and more specifically in health care management. They noted that strong research evidence demonstrating the effects of EBMgt practices on organizational performance was nonexistent.

\section{(2) What Is the Quality of the Evidence (Where It Exists) Regarding Evidence-Based Management?}

Using the assessment rubric described above, we rated $53.5 \%$ of articles in our dataset at the weakest level of evidence (Level 6); 16.0\% of the articles were Level 5; 8.3\% were Level 4; 9.0\% were Level 3; and 13.2\% Level 2. We did not rate any of the articles at the strongest level of evidence (Level 1). Figure 2 shows the number of articles by level of evidence.

In the text that follows, we explain the results for each level and provide examples of articles included in each category; all articles for each level of evidence are listed in the last column of Table 3.

Level 6. Approximately half (53\%) of all articles in our EBMgt dataset were of the weakest level of evidence (Level 6). These articles argued for (or against) EBMgt, but they were based on the author's opinion, sometimes backed up by anecdotes. We must note here that categorizing an article as Level 6 does not address whether the information presented is right or wrong. Neither does it assess the persuasiveness of the argument. What it does indicate is that the authors have neither presented research findings nor undertaken a systematic review of extant research to inform their arguments. In the Level 6 articles, authors may allude to research studies but do not provide information allowing readers to find those studies should they choose to do so. One example in this category is Rousseau (2006). Although, in our opinion, the article makes a compelling argument, claims regarding the importance and advisability of EBMgt are backed up by selected stories. Readers are not told the selection criteria. If managers choose to act based on a Level 6 article, they should realize that although the argument may be cogent and convincing, the level of evidence is weak.

Level 5. We classified approximately $16 \%$ of the articles in the dataset as generating Level 5 evidence. Evidence was generated through selfreport or descriptive studies providing an account of how one organization addressed a particular problem through the implementation of an innovative technique, process, or practice. The voice of these studies is subjective. For example, Dey (2006) reported on the local effectiveness of benchmark project management practices in a Caribbean public sector organization. Similar to

\section{Figure 2}

Number of Articles by Level of Evidence

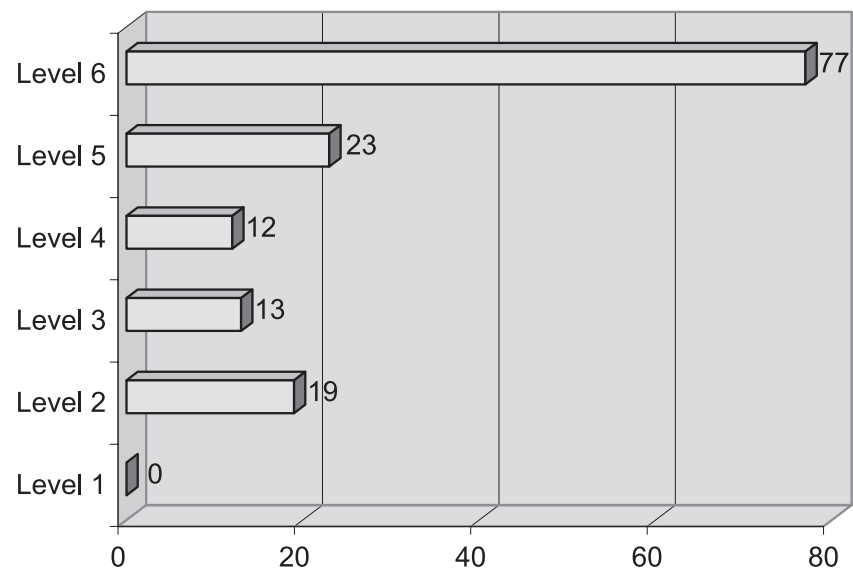


single cases reported by a physician in the medical research literature, the aim of this type of management article is to openly and honestly share lived experiences.

Level 5 articles describe promising practices with sufficient detail to allow readers the option of following up on cases presented. Promising practices are those that emerge as efficacious in one context and stand to inform decision making in other contexts. They are reported in studies that are less methodologically rigorous (i.e., descriptive with low internal or external validity) than studies with experimental or quasi-experimental design and high internal and external validity (Hall \& Jennings, 2008). Their appeal lies in their seeming applicability to other management contexts, but managers must be mindful that the effectiveness of promising practices in contexts other than those from which they emerged has yet to be demonstrated. An example is Pfeffer and Sutton (2006), where arguments are backed up by specific examples with explanations of how information was obtained. Articles of this type do not present research findings, but they do provide credible examples that deserve particular attention. Thus, evidence in Level 5 articles is stronger than in articles based on opinion, but still relatively weak since subjective cases or descriptive examples should be used as a model for management practice only with great caution.

Level 4. We identified $8 \%$ of the articles in our dataset as generating Level 4 evidence. They were based on small-sample or single-site studies following established research protocols and with a higher level of objectivity than self-reports. The studies were theoretically motivated and conducted by researchers who held at least an arm'slength relationship with the organization under study. One example is Zell et al. (2007), where researchers interviewed people within HewlettPackard Corporation (senior executives, managers, internal consultants, and clients) to determine how managerial strategies could accelerate both innovation and implementation. Since Level 4 articles are based on a recognized research approach, they provide assurance of trustworthy but not necessarily generalizable evidence. Managers working in a very similar context could feel rea- sonably confident about trying the practices presented.

Level 3. We classified $9 \%$ of the articles as generating Level 3 evidence. Based on quantitative or qualitative studies conducted across multiple organizations, these articles generate stronger evidence than Level 4 studies because they examine similar management practices in different contexts, thus improving the potential for generalizing the findings. Alexander et al. (2007), for example, conducted semistructured interviews with health care managers in eight different hospitals to identify ways to increase the use of research evidence in management practice. Managers searching for ways to address similar problems could reasonably try these practices unless they believed their current context to be entirely dissimilar to those examined in the research study.

Level 2. We rated $13 \%$ of the articles as Level 2 evidence. These were systematically conducted review articles. That is, the authors clearly established that their review was purposefully broad in scope, including both favorable and unfavorable results where they existed. One example is Ployhart (2006), where research on effective and ineffective staffing strategies was reviewed to critically analyze staffing best practices. Level 2 articles like this one provide state-of-the-art findings and give managers a clear picture of "what we currently know" about a particular management issue.

Level 1. We did not find any articles in our dataset that could be classified as generating Level 1 evidence. In accordance with medical research evidence levels, this type of article would be based on large-scale studies adhering to principles of random assignment or meta-analysis of previously published research. None of the articles in our dataset used these methodologies.

Since 1997 we note a marked increase in the number of published articles focusing on EBMgt. With this increase in numbers came an increase in the number of papers offering stronger levels of evidence; however, proportionally these did not increase by year. Instead, the number of papers citing weaker evidence-in particular Level 6 evidence-increased considerably from 1997 to the 
end of our dataset. Figure 3 shows the number of EBMgt publications, by level of evidence by year, over the study interval.

\section{(3) Is There Evidence That Employing Evidence- Based Management Will Improve Organizational Performance?}

The short answer to this question is no. None of the articles in our dataset addressed this question directly, which is a startling finding since this question is of utmost importance. The goal of evidence-based medicine is that physicians adopt practices most likely to improve patient outcomes. Similarly, organizational performance should improve as a result of adopting EBMgt (Kovner \& Rundall, 2006). Ideally, we would like to see studies that investigate whether organizations can improve performance (profitability or other measures) through EBMgt. It is this outcome of improved performance that should ultimately guide managerial practice, and studies addressing this question are currently absent.

\section{Discussion}

W hile EBMgt has been discussed for 60 years, we were surprised to find that most of the articles we reviewed were based only on weak evidence. The literature has yet to move much beyond Level 6 evidence-opinion pieces advocating the use of EBMgt. We agree with the few scholars who have found this lack of empirical support objectionable: It is not reasonable to ex- pect managers to practice EBMgt in advance of evidence demonstrating its impact on aspects of organizational performance. The argument for "evidence before action" (a golden rule in the medical research literature) is also relevant in the implementation of social interventions (Auerbach et al., 2007). Before taking action, managers require stronger evidence that demonstrates the value of EBMgt in improving organizational performance.

Although our review identified a majority of Level 6 articles, there were 23 Level 5 articles that we consider examples of promising practices (Hall $\&$ Jennings, 2008). These promising practices are worthy of highlighting, first because of the potential to extend these practices to management decision making beyond the original contexts, and second because they serve as a guide to management researchers by identifying particular areas worthy of exploration through more controlled methods. If promising practices constitute the "best available evidence," they can be a worthwhile focus for in-house experiments where managers conduct small-scale trials and carefully monitor results (Pfeffer \& Sutton, 2006).

While our search revealed no definitive evidence regarding the merit of implementing EBMgt to effect performance improvements, our review did reveal a small number of studies that approach this ideal. One (Beyer \& Trice, 1982) identified ways to improve research utilization. Two other studies (Gill \& Wong, 1998; Gooderham, Nordhaug, \&

\section{Figure 3}

\section{Number of Articles by Level of Evidence by Publication Year}

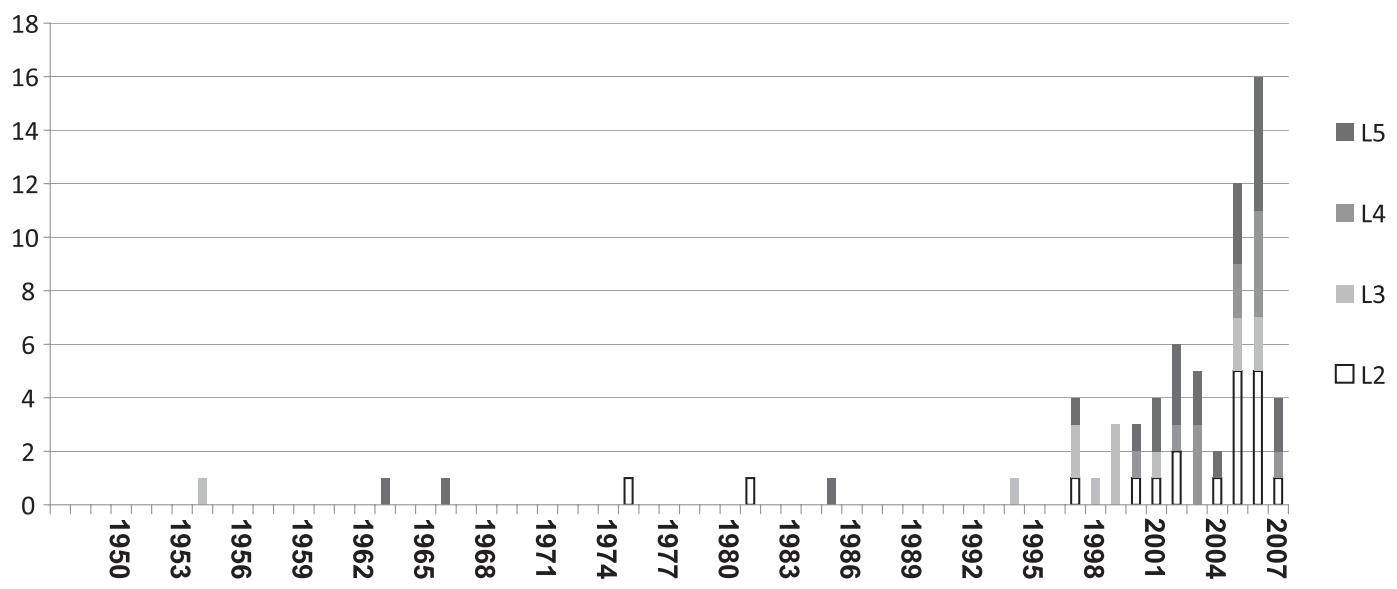


Ringdal, 1998) compared the adoption of managerial practices and found that some "best practices" for managers in one country were transferable, while others were not. A fourth study (Hamlin, 2002) found that managers following "best practices" received better performance appraisals than those who did not. All of these studies, however, fell short of linking the adoption of EBMgt practices to improved organizational outcomes. That said, all four of these studies are noteworthy as they offer research approaches that could be expanded to evaluate organizational performance indicators and thus identify potential consequences of adopting EBMgt practices.

Stronger evidence for EBMgt practice appears in a few management areas over others. Articles with a focus on human resource management generally offered stronger levels of evidence for adopting EBMgt practices than those regarding strategic management. Articles related to marketing also offered stronger levels of evidence for marketing decision making compared with other management areas. Figure 4 illustrates these differences across management areas. However, in spite of these differences, there was consistent concern about the lack of connection between research and practice. Stronger evidence did not seem to reduce the research-to-practice gap.

\section{Knowledge Translation}

In medicine, the literature on evidence-based practice has become increasingly focused on efforts to transfer and translate research findings to practice settings. This area of research, known as knowledge translation (KT), holds promise as a model for EBMgt. KT was born predominantly out of persistent variation in clinical practice, those very variations that evidence-based medicine seeks to overcome. In essence, variation arises in the process of implementing research evidence and is the consequence of a plethora of factors, including contextual barriers to uptake, perceptions of individual practitioners, the nature of the evidence itself, and the capacity of those generating evidence to prepare the evidence for its intended recipient. KT research in health care focuses on understanding how complex interventions, predicated on research evidence and involving multiple providers, recipients, and organizations, can be implemented (Auerbach et al., 2007; Smith \& Pell, 2003; Upshur, 2000, 2002). Since a key point for EBMgt is the transfer of

\section{Figure 4}

Number of Articles by Management Area by Level of Evidence

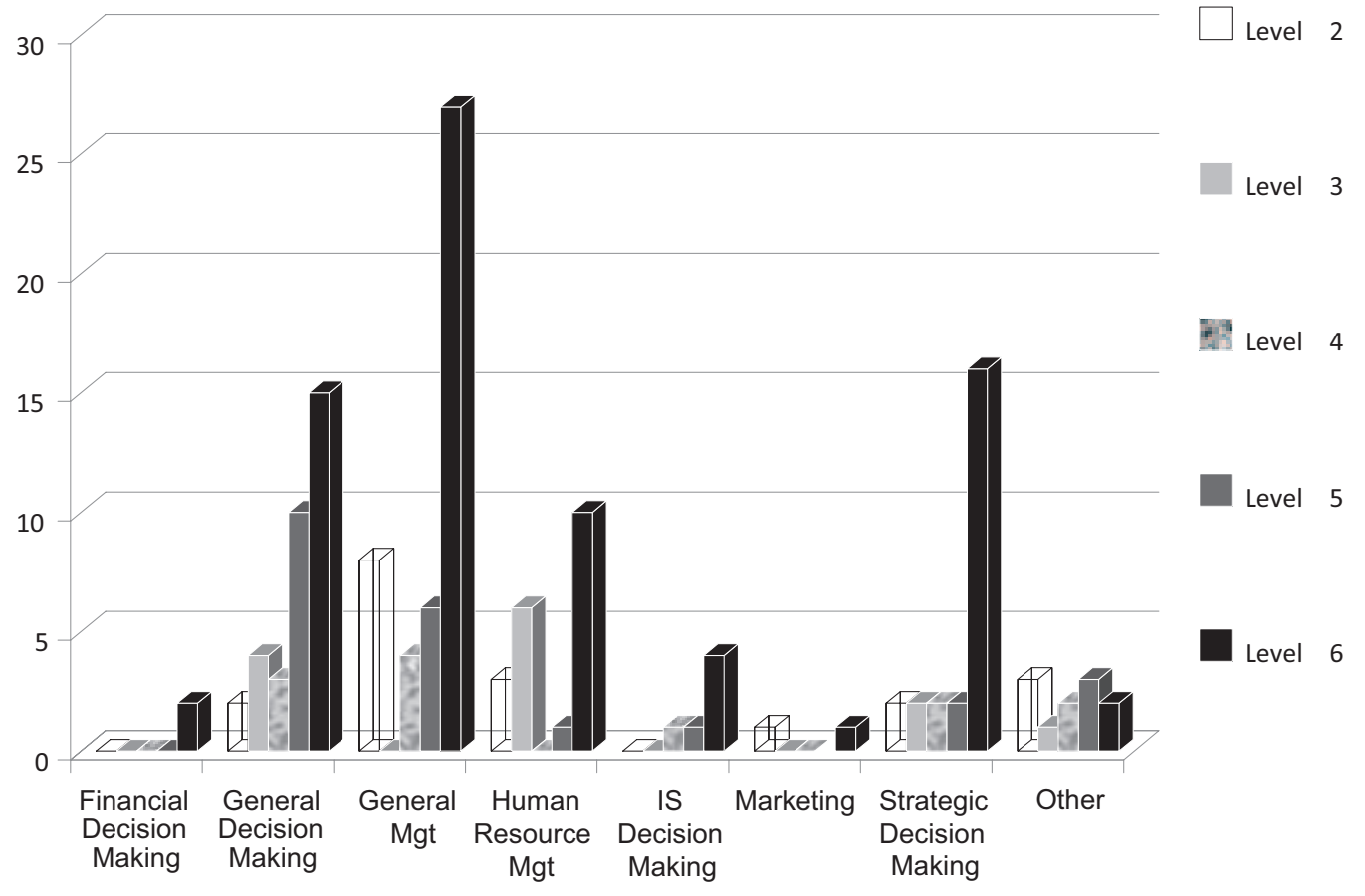


evidence from research to practice, lessons learned from KT research in health care could be used to inform initiatives in management settings.

Rousseau (2006) advocated for increased KT efforts, but from our systematic review, it seems that others have yet to take up the call. This is a missed opportunity, as there are many lessons that management could learn from $\mathrm{KT}$, with regard to both quality of evidence that should be put into practice and the methods by which researchers and practitioners can be brought together to facilitate EBMgt. What has been learned through $\mathrm{KT}$ research is that the existence of evidence is critical, but not sufficient to inspire and guide action. Changing practitioner behavior is difficult, despite the rigor of evidence that substantiates a particular behavior change (Kitson, Harvey, $\&$ McCormack, 1998). As a result, innovative and creative methods must be developed to bring evidence to practicing clinicians, managers, or other decision makers in order to overcome barriers to change (Straus, Tetroe, \& Graham, 2009).

Our review showed that the target audiences of EBMgt literature are primarily executives (56.3\%) and middle managers $(20.1 \%)$. Other target audiences were researchers $(10.4 \%)$, policy makers $(4.9 \%)$, and other $(8.3 \%)$. This suggests a number of interesting future research questions. For example: What are the most effective methods to facilitate the uptake of management evidence? Are the target audiences aware of the research aimed at them? Are these the appropriate audiences to target if sustained implementation is sought? The research design and presentation of results are both critical to uptake. Rynes, Giluk, and Brown (2007) showed that the extent to which evidence is honored in the translation varies considerably by publication. And according to Beyer and Trice (1982), "the most persistent observation ... is that researchers and users belong to separate communities with very different values and ideologies and that these differences impede utilization" ( $p$. 608). This concept of the two communities encompasses a belief that managers and academics hold differing perspectives, drives, and language (Jacobson, Butterill, \& Goering, 2003). Researchers and practitioners conceptualize problems in different ways, and thus conduct their work differently.

\section{Assessing the Evidence}

Our use of an assessment rubric for levels of evidence was critical to understanding and evaluating the literature on EBMgt. Similar to calls for change in medical practice, it is critical to make strong evidence available to management practitioners as part of the strategy for EBMgt. Management researchers and managers equipped with tools to assess different levels of research evidence can use the information to discriminate among evidence options, and to contribute to and benefit from the existing evidence base. Fundamental to EBMgt is the notion that decision making will be improved by searching for additional sources of evidence, ranging from Level 1 through Level 6. The assessment rubric is a tool for evaluating levels of rigor, suggesting that managers exercise caution when implementing strategies that are informed by weaker evidence. The scale of implementation should be commensurate with the level of evidence upon which a practice change is predicated. That is, a large-scale organizational change initiative should be premised on stronger levels of evidence, while more conservative approaches should be employed when the evidence is weak. In these cases in particular, organizational experiments or pilot projects should be implemented before large-scale investment is made.

\section{Limitations}

As referred to in an earlier footnote, a number of assessment rubrics and ranking tools have been developed to assist in the assessment of medical evidence. Upshur (2003) described five of the most commonly used ranking systems, all of which were the product of rigorous development processes that incorporated consideration of extant literature and the views, experiences, and opinions of experts in the generation and application of medical research evidence. We acknowledge that we did not engage in as rigorous a process to develop the assessment rubric used here; instead, we adapted one of those with which we had had prior experience (Barnsley et al., 2005; Berta et al., 2008, 2009) to fit the management literature 
and relied on our own collective expertise to orchestrate the fit. We consider the rubric to be helpful in terms of organizing the literature we reviewed; however, it merits further development. A more rigorous process that engages more and more varied experts in the management and implementation sciences is an important next step.

\section{Conclusions and Implications for Researchers and Managers}

W hile the concept of EBMgt has been a longstanding point of discussion in the management literature, there have been only modest advances in terms of research to substantiate the merit of EBMgt. A few earnest scholars have encouraged management researchers to rigorously examine the impacts of EBMgt practices on organizational performance, but thus far those encouragements have resulted in very limited success. Drucker (1955, 1967), Beyer and Trice (1982), and more recently Rousseau (2006) have set out much-needed research agendas for testing the efficacy of EBMgt, but there have been few responses on the part of management researchers. Although there has been a remarkable increase in the number of published articles devoted to the topic of EBMgt, we observe an unremarkable response in terms of articles generating stronger levels of evidence. In order to make the case for adoption of EBMgt practice, we need much more robust empirical research that shows a positive relationship between EBMgt practice and organizational performance.

There are some very practical considerations to address when encouraging management researchers to support EBMgt. If the goal is implementation, disseminating evidence is as important as generating it in the first place. How, then, do management researchers come to terms with balancing the competing priorities of generating high-quality research and also ensuring its dissemination to those who can put it into practice? One big step forward would be to modify current incentive structures that make it difficult for researchers to engage in knowledge translation efforts. In most academic settings, laudable management research must generate innovative findings and also make a strong contribution to theory. Research that strengthens the existing evidence base, such as thorough literature reviews or replication studies, gets far less attention and may even be difficult to publish.

To place the onus of EBMgt completely on management researchers-even if we were to remove the disincentives to engaging in $\mathrm{KT}$ - is entirely unreasonable. Managers must also be engaged. This can at least partially occur by teaching management students through an evidence-based approach (Rousseau \& McCarthy, 2007). We also see that it is critical to teach students how to evaluate research evidence so that when they become practicing managers they will be able to understand and appropriately apply new research evidence in practice. The assessment rubric we used could provide an important step toward achieving this goal by contributing to an overall strategy for developing the skills that future managers require to critically appraise evidence and determine the appropriate scale of implementation.

Recognizing the roles of both managers and researchers in EBMgt offers opportunities to bring the two communities together. First, researchers can pay attention to possible applications of their work and thus communicate their research findings in ways that highlight the practical implications. Second, when managers are equipped with the education and training that motivates and prepares them to seek out strong research evidence, they may provide encouragement for researchers. The field of management research could again follow the lead of health care in encouraging a collaborative approach to research with a combination of researchers and managers investigating questions that are important from a practice perspective. Several health care research funding bodies now require this type of collaboration. In addition, management (executive) education could include programs in which practitioners learn skills and develop supportive networks geared toward the ongoing evaluation and use of the "best available evidence."

In closing, we return to our original question: What's the evidence on evidence-based management? Our literature search leaves us with 
the following answers. First, we see that there are a large number of articles devoted to the topic, but most encourage adoption of EBMgt based on opinion and anecdotal information. This is really not sufficient evidence on which to base managerial changes, any more than we would encourage physicians to change their practice based on opinions and anecdotes. Conclusions about the impact of particular managerial actions should be based only on the results of rigorously conducted empirical research (Latham \& Locke, 2009). The lack of strong evidence for EBMgt leaves us with the clear conclusion that stronger, more rigorous empirical research related to the impact of EBMgt on organizational performance is severely lacking, and greatly needed. Because the evidence is weak, we should be cautious in our advocacy and aggressive in our pursuit of stronger research before promoting EBMgt to management practitioners. Similarly, managers and their organizations should scale their responses to "best management evidence" based on the strength of that evidence.

Second, our review shows that many articles have been written about promising practices. From these, we conclude that individual organizations are realizing successes from adopting EBMgt practices. But before we can fully advocate for EBMgt on a larger scale, we need research that compares and contrasts these localized initiatives in ways that help to illuminate transferable knowledge. These promising practices should be tested on a much broader scale, and this can be done by researchers or insightful managers who document their implementation efforts and results achieved.

Finally, we see that although the current evidence base for EBMgt is weak, there is potential for the future. As practicing managers become more aware of the strength of evidence, they are likely to demand stronger evidence to make a business case for change. This means that management consultants, practitioner journals, and researchers will need to provide stronger evidence for their claims, resulting in a much stronger evidence base overall.

\section{References}

Alexander, J. A., Hearld, L. R., Jiang, H. J., \& Fraser, I. (2007). Increasing the relevance of research to health care managers: Hospital CEO imperatives for improving quality and lowering costs. Health Care Management Review, 32, 150-159.

Arndt, M., \& Bigelow, B. (2007). Evidence-based management in health care organizations: A critique of its assumptions. Academy of Management Proceedings, 2007, $1-6$.

Auerbach, A. D., Landefeld, C. S., \& Shojania, K. G. (2009). The tension between needing to improve care and knowing how to do it. New England Journal of Medicine, 357(6), 608-613.

Barnsley, J., Berta, W., Cockerill, R., MacPhail, J., \& Vayda, E. (2005). Identifying performance indicators for primary care practices: A consensus process. Canadian Family Physician, 51(5), 700-701.

Berta, W., Barnsley, J., Bloom, J., Cockerill, R., Davis, D., Jaakkimainen, L., Mior, A. M., Talbot, Y., \& Vayda, E. (2008). Enhancing continuity of information: Essential components of a referral document. Canadian Family Physician, 54, 1432-1433.e6.

Berta, W., Barnsley, J., Bloom, J., Cockerill, R., Davis, D., Jaakkimainen, L., Mior, A. M., Talbot, Y., \& Vayda, E. (2009). In search of high informational continuity: Identifying essential elements of consultation reports. Canadian Family Physician, 55, 624-625.e5.

Beyer, J. M., \& Trice, H. M. (1982). The utilization process: A conceptual framework and synthesis of empirical findings. Administrative Science Quarterly, 27, 591-622.

Cascio, W. F. (2007). Evidence-based management and the marketplace for ideas. Academy of Management Journal, 50(5), 1009-1012.

Conant, J. B. (1948). The place of research in our national life. Harvard Business Review, 26, 46-57.

D'Agostino, R. B., \& Kwan, H. (1995). Measuring effectiveness: What to expect without a randomized control group. Medical Care, 33, AS95-AS105.

Dey, P. K. (2002). Benchmarking project management practices of Caribbean organizations using analytic hierarchy process. Benchmarking, 9, 326-356.

Drucker, P. (1955). Management science and the manager. Management Science, 1, 115-126.

Drucker, P. (1967). The effective decision. Harvard Business Review, 45, 92-98.

Feinstein, A., \& Horwitz, R. I. (1997). Problems in the evidence of evidence-based medicine. American Journal of Medicine, 103, 529-535.

Gill, R., \& Wong, A. (1998). The cross-cultural transfer of management practices: The case of Japanese human resource management practices in Singapore. International Journal of Human Resource Management, 9, 116-135.

Gooderham, P. N., Nordhaug, O., \& Ringdal, K. (1999). Institutional and rational determinants of organizational practices: Human resource management in European firms. Administrative Science Quarterly, 44, 507-531.

Hall, J. L., \& Jennings, E. T. (2008). Taking chances: Evaluating risk as a guide to better use of best practices. Public Administration Review, 68, 695-708. 
Hamlin, B. (2002). Towards evidence-based management and research-informed HRD practice: An empirical study. International Journal of Human Resources Development and Management, 2, 160-169.

Hewison, A. (2003). Qualitative management research in the NHS: A classic case of counting to one? Journal of Health Organization and Management, 17, 122-137.

Jacobson, N., Butterill, D., \& Goering, P. (2003). Development of a framework for knowledge translation: Understanding user context. Journal of Health Services Research and Policy, 8, 94-99.

Kitson, A., Harvey, G., \& McCormack, B. (1998). Enabling the implementation of evidence based practice: A conceptual framework. Qual Health Care, 7, 149-158.

Kovner, A. R., \& Rundall, T. G. (2006). Evidence-based management reconsidered. Frontiers of Health Services Management, 22, 3-22.

Latham, G. P., \& Locke, E. A. (2009). Science and ethics: What should count as evidence against the use of goalsetting? Academy of Management Perspectives, 23, 88-91.

Ovretveit, J. (2005). Leading improvement. Journal of Health Organization and Management. 19, 413-430.

Pfeffer, J., \& Sutton, R. I. (2006). Evidence based management. Harvard Business Review, 84, 62-74.

Ployhart, R. E. (2006). Staffing in the 21st century: New challenges and strategic opportunities. Journal of Management, 32, 868-897.

Rousseau, D. M. (2006). Is there such a thing as "evidence based management"? Academy of Management Review, $31,256-269$.

Rousseau, D. M. (2007). A sticky, leveraging, and scalable strategy for high-quality connections between organizational practice and science. Academy of Management Journal, 50, 1037-1042.

Rousseau, D. M., Manning, J., \& Denyer, D. (2008) Evidence in management and organization science: Assembling the field's full weight of scientific knowledge through synthesis. Academy of Management Annals, 2, 475-515.

Rousseau, D. M., \& McCarthy, S. (2007). Educating managers from an evidence-based perspective. Academy of Management Learning Eु Education, 6, 84-101.

Rynes, S. L., Giluk, T. L., \& Brown, K. G. (2007). The very separate worlds of academic and practitioner periodicals in human resource management: Implications for evidence-based management. Academy of Management Journal, 50, 987-1008.

Smith, G. C. S., \& Pell, J. P. (2003). Parachute use to prevent death and major trauma related to gravitational challenge: Systematic review of randomized controlled trials. BMJ, 327, 1459-1461.

Straus, S., Tetroe, J., \& Graham, I. D. (2009). Knowledge translation in health care: Moving from evidence to practice. Chichester, UK: John Wiley \& Sons Ltd.

Upshur, R. (2000). Seven characteristics of medical evidence. Journal of Evaluation in Clinical Practice, 6, 93-97.

Upshur, R. (2001). Meaning and measurement: An inclusive model of evidence in health care. Journal of Evaluation in Clinical Practice, 7, 91-96.

Upshur, R. (2002). If not evidence, then what? Or does medicine really need a base? Journal of Evaluation in Clinical Practice, 8, 113-119.

Upshur, R. (2003). Are all evidence-based practices alike? Problems in the ranking of evidence. Canadian Medical Association Journal, 169, 672-673.

Walshe, K., \& Rundall, T. G. (2001). Evidence-based management: From theory to practice in healthcare. Milbank Quarterly, 79, 429-457.

Young, S. K. (2002). Evidence-based management: A literature review. Journal of Nursing Management, 10, 145151.

Zell, D. M., Glassman, A. M., \& Duron, S. A. (2007). The short and glorious history of accelerated decision making at Hewlett-Packard. Organizational Dynamics, 36, 93104. 